\title{
A burning topic: Tobacco and death
}

Our goal is to be the most responsible, effective and respected developer, manufacturer and marketer of consumer products, especially products intended for adults. Our core business is manufacturing and marketing the best quality tobacco products to adults who choose to use them.

Philip Morris USA (1)

A Miami jury has ordered the major tobacco companies to pay $\$ 145$ billion dollars. All the tobacco companies are crying bankruptcy. They say they may go broke. Today the head of one company said if this judgement stands they may have to go into another line of killing. Jay Leno (2)

$\mathrm{T}$ obacco-induced illnesses continue to plague the world. Projections are routinely published showing that chronic obstructive pulmonary disease and lung cancer are becoming the world's largest killers. The World Health Organization predicts that, by the year 2020, there will be 8.4 million deaths annually attributable to smoking (3). That is increased from the mere four million annual deaths in 2001. In contrast, the World Health Organization estimates that the worldwide toll from acquired immune deficiency syndrome in the year 2001 will near three million deaths. I do not wish to trivialize the devastation that acquired immune deficiency syndrome causes worldwide, but rather, to put deaths from cigarettes into an appropriate global perspective. As Canadians, we may smugly assume that we are winning the battle against tobacco addiction. There are proportionately fewer Canadians who are expected to die from cigarettes in the next two decades. However, the absolute numbers of deaths from smoking is anticipated to increase by $50 \%$ in the developed nations. As well, deaths from smoking are expected to rise disproportionately in the developing world. Asia will be one of the regions that is hit the hardest, with the death rate from tobacco expected to increase fourfold over its current level. The toll in human life and suffering is almost unimaginable. In 1994, mass slaughter in Rwanda resulted in 800,000 deaths in just 100 days. In 2020, the number of deaths from tobacco will equal that of three Rwandan massacres every 100 days. If, in the year 2020, we were to stack each person who died a smoking-induced death one atop the other, we could build a column of bodies reaching $180 \mathrm{~km}$ into the sky. If we would continue to pack these bodies one atop the other for just one more year, a warning light would have to placed at the apex of this column to prevent the International Space Station from ploughing into this grotesque metaphor. These analogies become increasingly difficult to conceptualize, but this will be our future if we allow the carnage to continue unabated.

We can take these nameless hoardes and put faces to them. The country grieved this past January when Canada lost one man to cigarettes. Peter Gzowski was unique for many reasons, and his loss was felt by many Canadians on a personal level. Cigarettes took his breath away and silenced his voice. We should not lose sight of the

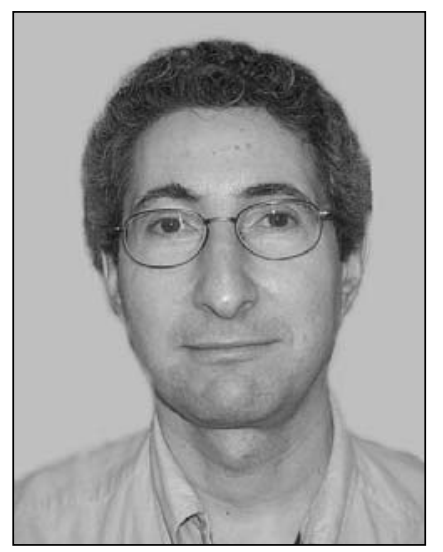

Irvin Mayers individual tragedies due to tobacco-induced deaths that occur every day. People all across our country regularly lose fathers, mothers, brothers, sisters, neighbours and friends due to tobacco. We should grieve for all of the people who died prematurely due to this addiction. As members of the Canadian pulmonary community, we should be strong advocates in supporting our patients in attempts at smoking cessation and in treating the nicotine addiction. I believe that we also have broader societal obligations to treat the country and not just the individual.

There are a variety of lay groups currently attempting to reduce tobacco use in the country, not the least of which is the Canadian Lung Association. However, other physicianled groups in North America such as the American College of Chest Physicians are developing and financing smoking cessation programs. Is this a route that the Canadian Thoracic Society (CTS) should be taking? The CTS has traditionally been a strong advocate for clinical and basic science research in Canada. Is it time for us to become more involved in lobbying regional, provincial and federal governments to help to set policy? Tobacco taxes from across 
the country are used to support the general revenue needs of our governments. Thanks to this influx of dollars, our personal taxes do not need to increase to pay for our current social programs. Should the CTS be advocating that a portion of these dollars go back to pay directly for smoking cessation programs and to pay for the research needed to evaluate properly the outcomes of these programs? This would require a clear and strong commitment from our membership to offer their time and expertise to help achieve some long term goals. We all acknowledge that many of the anticipated near-term deaths are unavoidable. However, I believe we should be clearly telling our governments that a $50 \%$ increase in tobacco deaths by 2020 is not a number in which we take solace. Instead, I am suggesting that, as a community, we should be aiming to achieve an absolute reduction of $50 \%$ in cigarette use by the year 2020 . I would appreciate feedback and comments on how we could use our collective knowledge and advocacy to achieve this outcome (e-mail imayers@ualberta.ca). Until our current epidemic of tobacco addiction is curbed, the pile of bodies will continue to grow higher until it bridges the space to our nearest neighbouring planets.

Irvin Mayers MD FRCPC

President, Canadian Thoracic Society

\section{REFERENCES}

1. Philip Morris USA. Our Mission and Values. <http://www.philipmorrisusa.com/DisplayPageWithTopic.asp?ID=63> (Version current at February 21, 2002)

2. Jay Leno. Quick Quips, July 20, 2000. <http://humor.about.com/library/quote/blquip072000.htm?iam= dpile\&terms $=$ Jay + Leno + Tobacco $>$

(Version current at February 21, 2002)

3. Murray CJL, Lopez AD. World Health Report, 1999.

$<$ http://tobacco.who.int/> (Version current at February 21, 2002) 


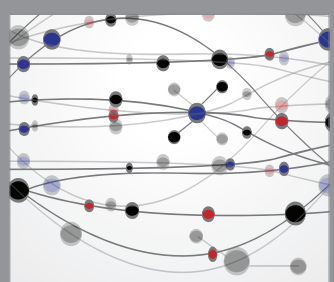

The Scientific World Journal
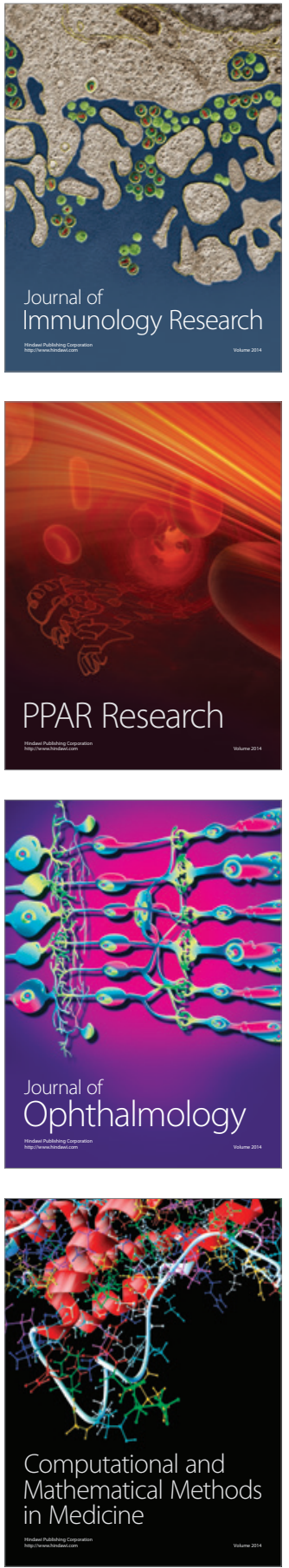

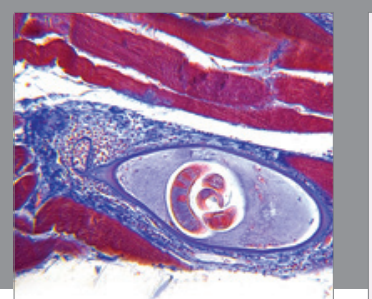

Gastroenterology Research and Practice

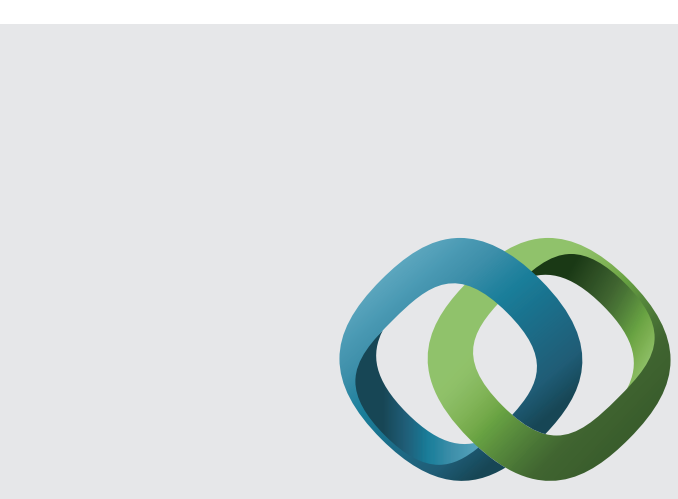

\section{Hindawi}

Submit your manuscripts at

http://www.hindawi.com
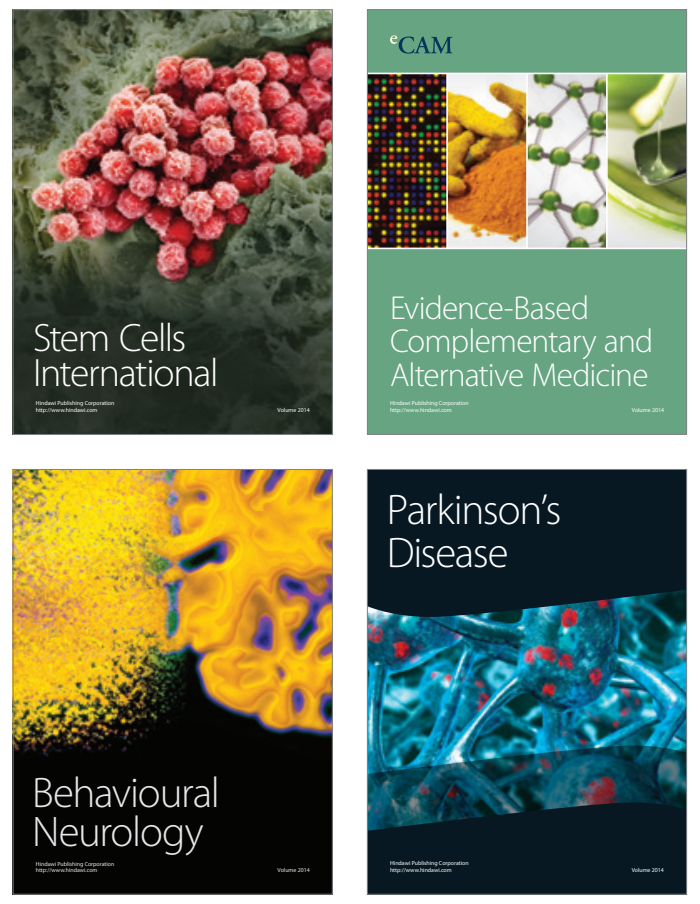
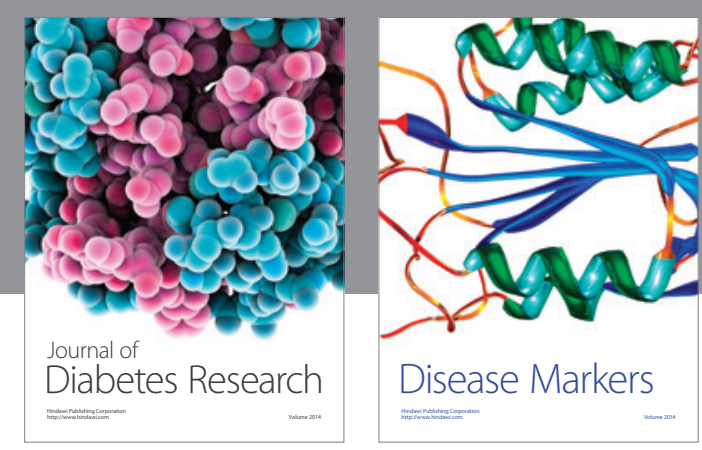

Disease Markers
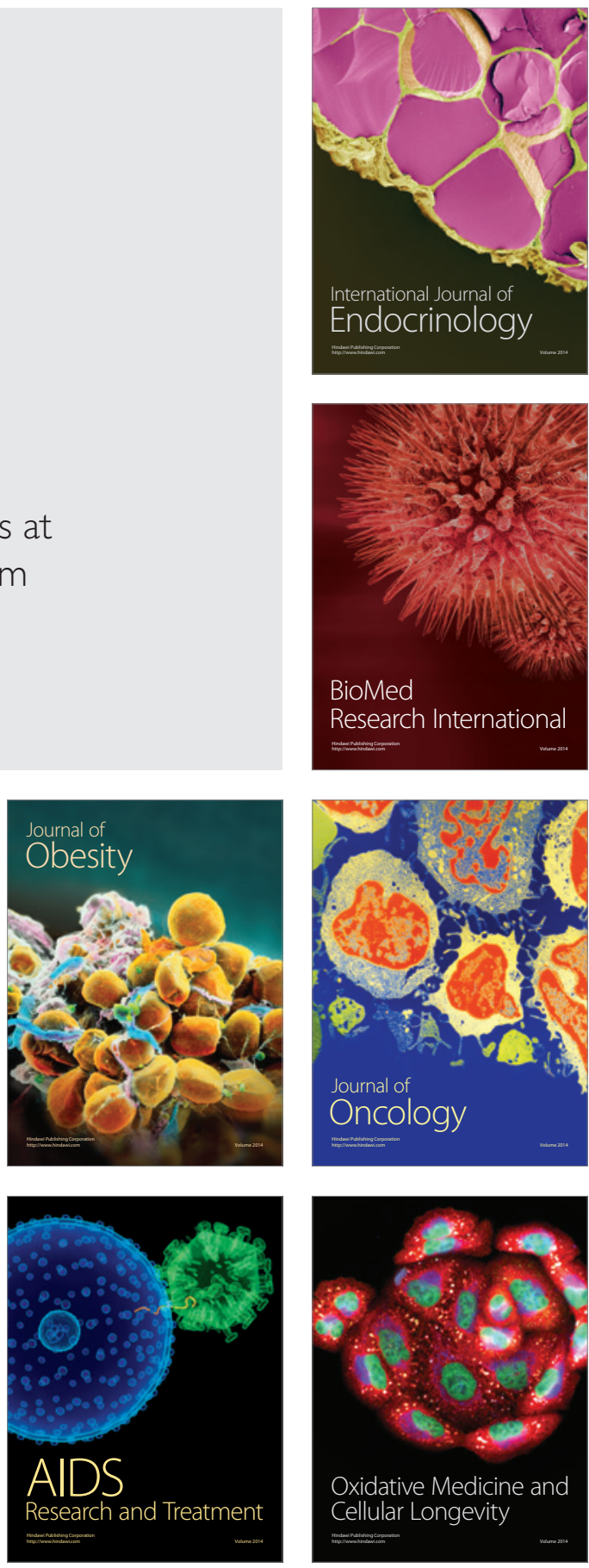